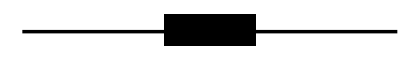

\title{
Introduction
}

\section{Environment, Society, and Food}

\section{Rebecca Feinberg, Paige West, and Dan Brockington}

During the past two decades social scientists have paid an increasing amount of attention to the circulation of commodities and the effects that commodity production, distribution, and consumption have on social life (see Miller 1995). Today, social scientists are beginning to think carefully about the political ecologies of these same commodity circulations (see Bryant and Goodman 2004; Doane 2010; West 2012). We are exploring the environmental consequences of the creation, circulation, and consumption of commodities, the role of nature in shaping the commodity form, their circulation and resulting social life, and the broader political economy in which commodity circulation is found.

Food is an obvious and important entry point into the analysis of both commodity circulation and political ecology. It is important both as the commodity we consume most frequently and most intimately. Food becomes us corporeally, it changes us physically; it is a vital part of our personal, regional, and national identities, as well as the driver of, and accompaniment to, much of our social activity. Agriculture is one of the main drivers of land use change and one of the most extensive forms of land cover. Whether in the form of unrest over food prices, or protest about its industrialized production, food gets people motivated in unusual ways.

Much of the current literature on food in the social sciences fits into three categories: literature that follows food from production to distribution to consumption (the commodity chain approach), literature that focuses on the meanings attributed to foods as they circulate (the semiotics of circulation or commodity circuit approach), and literature that focuses on the lives of producers and where they fit in global political economic structures (the political economy approach). Collectively the work in these approaches provides an excellent lens with which to examine current dilemmas in social science. In particular it helps us understand different aspects of what has been called "globalization." There is now a strong contemporary literature drawing on rich histories of the analysis of agriculture, social life, and political economy from anthropology, geography, sociology, and history.

In this issue of Environment and Society: Advances in Research we bring together some of the insights that studying food can provide-both what they tell us with regard to food specifically, and about commodity chains, semiotics, and political economies more generally. There is a persistent theme throughout the articles; namely most take a long hard look at the transformative potential of different schemes that hope to alter the injustices and ecological violence that our food commodity chains can create. The result is not always encouraging reading but the quality of the scholarship is bracing. 
Cindy Isenhour's article evaluates the impact of consumer-based alternative food movements with the aim of answering the question, "Can Consumer Demand Deliver Sustainable Food?" The question is not limited to food commodity chains alone. There is a great deal of faith in the ability of consumers to change commodity chains through their purchasing decisions, in everything from clothes to energy to diamonds to tourism destinations. What sort of change they can create matters a great deal. Isenhour, by studying consumer-based movements as a category, examines the ideas at work within these initiatives and connects her central question to issues of individual agency, trends in sociopolitical culture, and inequality within the global system of production and consumption. The article outlines the promises and pitfalls of a variety of movements, demonstrating consumer-based movements' capacity to effect change, but perhaps more importantly their theoretical and practical limitations. Although consumer power is considerable, Isenhour-after an extensive and scholarly review-argues that it operates within the limits of power structures that it would be unreasonable to expect consumers to take on. Vesting too much hope in consumer power risks vesting too much responsibility on individuals to take on complex and powerful systems.

Following on from this general evaluation, Debarati Sen and Sarasij Majumder present a specific case study of consumer-driven movements. They evaluate the Fair Trade movement's success in restoring ethics to the economics of food and contesting structural inequalities within the global economy between the North and the South, with a particular focus on what the demands and rewards of Fair Trade can do to social relations in the producing communities. Their article draws upon interdisciplinary studies on Fair Trade as well as ethnographic work that illustrate the diverse outcomes of the movement. The authors argue that while Fair Trade certification has become a biopolitical regime that can act as a governing mechanism on Southern producers, constraining their lives and livelihoods, it also holds the potential for reflecting global counterpolitics. The producers themselves can, through the presence of Fair Trade, become more conscious and more active about their entitlements with the result that, in unexpected ways, Fair Trade has emancipatory potential.

Shaila Seshia Galvin examines the role of organic certification in the rapidly expanding organics sector. Drawing upon scholarship on organics and food movements, as well as fieldwork with organic smallholders in northern India, she illustrates both the diversity and complexity of organic certification and questions the extent to which it accomplishes or undermines its stated goals. Galvin concludes that the future of organic certification will be shaped by issues of trust and audit culture, quality and conventionalization, and by our understanding of the relationship between "nature" and human agency.

In "Mapping the Food Movement: Addressing Inequality and Neoliberalism," Teresa Mares and Alison Alkon investigate two main criticisms of alternative food movements, namely local food, community food security, food justice, and food sovereignty. In their comparison of these movements, they discuss the inequalities related to race and class in food production and consumption, and the neoliberal constraints of market-based solutions to systematic problems. Illuminating the fundamental differences between the first three movements and food sovereignty, the authors suggest the potential of food sovereignty to dismantle the historical and structural obstacles to more democratic and sustainable food systems.

Hannah Wittman's article takes a closer look at food sovereignty. Wittman presents a cohesive picture of the theoretical and methodological development of food sovereignty as an alternative approach to current food security thinking and practice. She explores the possibilities of a rights-based approach, grounded in agrarian citizenship and an agrarian moral economy, to reforming the dominant food regime, and reviews the demands and strategies of the food sovereignty movement, highlighting opportunities for future action and research. 
Fabio Parasecoli and Aya Tasaki's concern is the role of geographical indications that are awarded to particular regional specialty products. Their concern is whether such labeling can protect agro-biodiversity and traditional knowledge, as well as to ensure the livelihood of rural communities in emerging economies. Drawing from both scholarly literature and policybased material, the article discusses the legal, logistical, sociological, and ecological aspects of geographical indications as a form of cultural preservation, economic security, and environmental stewardship. The authors observe that the promise and potential of geographical indications for adding value to particular food and regional economies does come with significant constraints.

Shaun Ruysenaar takes on the highly charged biofuel versus food debate. He presents first the complexity of issues that lie behind the "food versus fuel" debates globally, and then explores the way the issue is being contested in South Africa, where local food insecurity, a strong corporate maize interests, and food price rises have made this a tense issue. He argues that current debates focus on either the implications for food prices or rural development, when in fact the two are interlinked. The real problem underlying these debates is that the agricultural political economy remains riven with injustice, which the debate over biofuels is not yet addressing.

Rogers-Brown, Shearer, and Harthorn offer a prescient review of an emerging topic-the public perception of nanotechnology in food and agriculture. This is a new field, but one which is likely to become more discussed in the future. Unusually for the journal, this article is distinguished by the authors' use of their own research from six deliberative workshops on nanotechnology in 2009 in the United States. Our intimate relationship to food makes nanotechnology a contested area for the application of emerging technologies, and the authors provide evidence that the concerns raised by global consumers and activist organizations about biotechnological alteration of food are material examples of unresolved social issues involving technologies and food, including access to information, government regulation, and corporate responsibility.

Finally, Joanna Mosser's article critiques the misrecognized omnipresence of the state-as both an institution and an idea-in the way we think, speak, and act in everyday life. Her particular complaint is the way in which we learn, or rather fail to learn, about the role of the state in "enviro-cidal" alliances of neoliberalism and governments, for which she draws on her own experience in the political science classroom. In order to fully understand both the development of the food and environmental movements discussed in this journal and elsewhere, Mosser demonstrates the epistemology of the state's power in shaping our concept of ourselves as largely passive individual consumers, rather than independent authors or collective actors in ecological policy and practice.

\section{ACKNOWLEDGMENTS}

Our thanks to all the authors, numerous reviewers, and colleagues who have supported the development of this issue. Dan Brockington would particularly like to thank Rob Edwards for his struggles with our current food systems, and for fighting for something better.

\section{REFERENCES}

Bryant, Raymond L., and Michael K. Goodman. 2004. "Consuming Narratives: The Political Ecology of 'Alternative' Consumption." Transactions of the Institute of British Geographers 29, no. 3, 344-66. 
Doane, Molly. 2010. "Relationship Coffees: Structure and Agency in the Fair Trade System.” Pp. 229-257 in Fair Trade and Social Justice, ed. Sarah Lyon and Mark Moberg. New York: New York University Press.

Miller, Daniel, ed. 1995. Acknowledging Consumption: A Review of New Studies. London: Routledge.

West, Paige. 2012. From Modern Production to Imagined Primitive: The Social World of Coffee from Papua New Guinea. Durham: Duke University Press. 